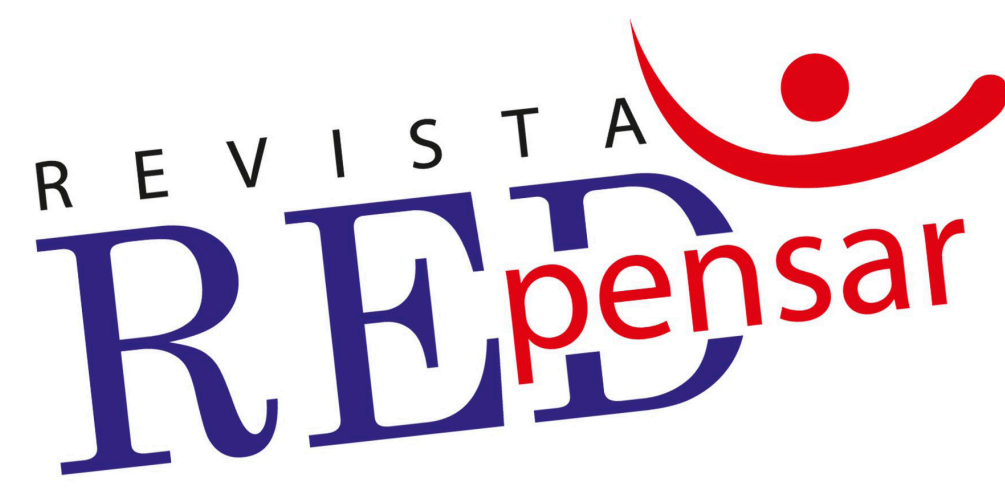

\title{
Diversidad y Cuidado: \\ Desde una mirada vincular
}

\section{Diversity and Care: \\ From a linked perspective \\ Maria Cristina Ventura (Tirsa)}

Revista REDpensar, volumen 8, número 1, Enero-Junio 2019 ISSNe: 2215-5384

Lanzando la RED 1

Recibido: 04 de marzo de 2019 Aceptado: 06 de mayo de 2019

DOI: 10.31906/redpensar.v8.i1.179

\section{(이(1)(2)}




\title{
Diversidad y Cuidado: Desde una mirada vincular
}

\author{
Diversity and Care: \\ From a linked perspective
}

Maria Cristina Ventura (Tirsa) ${ }^{1}$

Que existen vientos nuevos, que se pueden escuchar, respirar otros rostros, otras prácticas, otros modos de valorar el mundo y las personas, otras formas de relacionarnos, de caminar. Otras maneras de aprender, gustando, sintiendo, amando...

(autoría propia)

\section{Resumen}

Este trabajo visa reflexionar sobre la diversidad y el cuidado, contra toda forma de pensamiento y acción exclusivista, fragmentado, centrado en la norma y la normatividad como lugar privilegiado de poder, elevando la atención de y entre lo humano y de este con el medio. Se plantea desde cuatro momentos importantes: el primero una breve introducción en que se propone presupuestos epistémicos basados en un pensamiento planetario y los vínculos como ejes articuladores de relaciones transformadoras. Para esto, nos apoyamos en autores como Judith Buther, Gayati Spivak, Giorgio Agamben. El segundo, consiste en una mirada atenta al contexto y las crisis que lo caracterizan, con el cual se formulan las preguntas generadoras que van a orientar el proceso de reflexión, para lo cual nos dejamos orientar con autores como Boaventura de Sousa Santos y Denise Najmanovich. El tercer momento, trabaja el ámbito de la educación, a partir de una mirada crítica para desde ahí proponer un abordaje desde la diversidad y el cuidado. En el cuarto momento, a partir de una propuesta de lectura bíblica, se hace un ejercicio de deconstrucción de paradigma normalizador, que sostiene una visión de la religión, basada en un ser supremo lejos de la historia, lo que permite la emergencia de una nueva comprensión de diversidad y cuidado que sólo es posible desde una mirada vincular.

Palabras Clave: DIVERSIDAD, CUIDADO, MIRADA VINCULAR, RELIGIÓN, NORMATIVIDAD, NORMA.

\section{Abstract}

This work aims to reflect on the diversity and care, all forms of thought and exclusivist, fragmented action, focusing on the rule and regulations as a privileged place of power, raising attention and between human and this with the

1. República Dominicana. Dra. en Ciencias de la Religión, Universidad Metodista de São Paulo, y Dra. en Educación con énfasis en Mediación Pedagógica. Docente e investigadora en Universidad La Salle. Correo electrónico: tventura@ulasalle.ac.cr 
medium. It arises from four important moments: the first a brief introduction in which epistemic assumptions based on planetary thought and links are proposed as articulating axes of transforming relationships. For this, we rely on authors like Judith Buther, Gayati Spivak, Giorgio Agamben. The second consists of an attentive look at the context and the crises that characterize it, with which the generating questions are formulated that will guide the reflection process, for which we allow ourselves to be guided by authors like Boaventura de Sousa Santos and Denise Najmanovich. The third moment works in the field of education, from a critical perspective to from there propose an approach from diversity and care. In the fourth moment, based on a proposal for biblical reading, an exercise in deconstruction of the normalizing paradigm is carried out, which supports a vision of religion, based on a supreme being far from history, which allows the emergence of a new understanding of diversity and care that is only possible from a linking perspective.

Keywords: DIVERSITY, CARE, LINKED PERSPECTIVE, RELIGION, NORMATIVITY, NORM.

\section{Introducción: Presupuestos epistemológicos}

Se apunta a una comprensión de la diversidad como categoría que emerge contra toda forma de pensamiento y acción exclusivista, centrado en la norma y la normatividad como lugar privilegiado de poder, donde se lleva a cabo una producción diferencial de lo humano. De esta manera, se trata del reconocimiento de una diversidad que pone en cuestión los estándares de normalización que han llevado a asumir cuadriculas morfológicas de diferentes índoles, entre las que destaco, raciales, sexuales, todas propuestas que se toman el derecho de definir aquello que vale como humano y como menos que humano o aún peor, como no humano (Buther, 2004).

Frente a esto, me anima la propuesta de un pensamiento planetario, donde podamos imaginarnos a nosotros mismos como criaturas planetarias, contenidas en una alteridad que no deriva de nosotros, sino que nos contiene y a la vez nos arroja lejos de sí (Gayati Spivak, 2003, pp.92-93). Dicho de otro modo, se trata de pensar un sujeto planetario que, con su nuda vida expuesta al mundo, existe sin una cartografía ya preestablecida y sólo puede ser reparable como responsabilidad en relación con los otros (Agamben, 2013). Esto nos exige pensar en nosotros mismos no como entes individuales definidos contra los otros, sino más bien, en relación con, conectadas con y así elevar a la trama como el modo de existir. Y por eso, la única manera de pensar en ecología, es la conexión y el vínculo.

Vale destacar también, que el propio devenir como individuo es un proceso de muchos niveles, no sólo en relación con las personas con las cuales nos relacionamos, las estructuras políticas y sociales que configuran las posibilidades, los esfuerzos que se hacen para permanecer enraizadas en los ritmos de la creación, sino también en las maneras en que somos capaces de usar la dinámica vincular como clave para el crecimiento personal y la autocomprensión.

El planteamiento anterior me permite trabajar la propuesta, desde una mirada de conexión, o mejor, una mirada vincular del mundo. Por lo tanto, se trata de pensar y actuar a partir de un pensamiento no dualista, sino más bien, desde una mirada del mundo basada en las conexiones. Esto me conduce a afirmar que lo que se requiere no es la eliminación del otro o la retención del otro como una categoría dominante, sino el respeto y el compromiso con el bienestar del otro en su diversidad.

Y digo vincular porque se trata de maneras de conectarnos que no están preestablecidas, sino que surgen en la misma dinámica del vivir. Por eso, me animé abrir este trabajo con el poema, de mi propia autoría, porque este trabajo quiere ser una invitación a un mirar nuevo, más allá de lo mismo, pero, sobre todo, una invitación al vínculo que surge y genera afectos, porque surgen de la diversidad y del cuidado que permiten re-existir. 
Nuestras miradas, en los tiempos actuales, están enfocadas en el gran acontecimiento de la pandemia. Quienes tienen la posibilidad, tienen la atención puesta en lo que cada día narran las cadenas de noticias nacionales o internacionales. El Covid-19 llega como el gran relato de los últimos tiempos: causa muerte de miles de personas en el mundo, principalmente personas adultas mayores y ancianas. Las preocupaciones andan por ¿cómo no infectarnos?, ¿cuándo anunciarán la vacuna?, ¿cuándo se podrá salir libremente del confinamiento? ¿cuándo iniciarán las escuelas?

Pero, a la par de esas preguntas, otras preocupaciones resuenan y vienen de hace mucho tiempo, causadas por el empobrecimiento social que viven millones de personas, porque como señala Boaventura de Sousa Santos (2020), al referirse a la crisis financiera permanente y la crisis generada por el Covid-19, "la pandemia solo agrava una situación de crisis a la que ha sido sometida la población mundial. Es por ello por lo que implica un peligro específico" (p.20). Este sometimiento genera diversos modos de presencia, los cuales definen las maneras diferentes en que somos o no parte del engranaje eco-sociopolítico-religioso-cultural. Y presto atención a los cuerpos, cada uno representando un ecosistema. En definitiva, formando una comunidad que arroya una sola sombra: la diversidad. Ellos son el espacio preferencial en que se manifiestan los elementos de ese engranaje.

Y, entonces, otras preguntas surgen, yo diría, con otros toques existenciales ¿cuándo vamos a poder tener acceso a una alimentación sana?, ¿cuándo se podrá trabajar para conseguir el pan?, ¿cuándo pasará el infierno de la violencia doméstica, mientras dura el confinamiento por el Covid-19, pero también el confinamiento patriarcal sexista, racista y xenófobo?

El panorama se vuelve complejo, por lo tanto, exige una mirada compleja. En este sentido, es útil preguntar no sólo por cómo no nos infectamos con el virus, sino también cómo nos dejamos afectar de estos modos distintos de habitar, principalmente cuando se trata de crisis causadas por fenómenos tan antiguos como el patriarcado, conocido también como "contrato de lo socio-simbólico" (Kristeva,1982, p.42) el cual muestra la inevitabilidad de la exclusión de las mujeres y el rechazo del significado distinto de la sexualidad femenina. Así también, por la exclusión de sistemas de leyes que legitiman el saqueo de los bienes de la naturaleza, o los sistemas de salud que no toman en cuenta a las personas vulnerables.

En palabras de Boaventura de Souza Santos (2020), la pandemia actual solo empeora una situación de crisis a la que ha sido sometida la población mundial, en un contexto en que 'el capitalismo neoliberal ha incapacitado al Estado para responder a emergencias'. En este sentido, la pandemia actual no es una situación de crisis claramente opuesta a una situación "normal". La pandemia de coronavirus es una manifestación entre muchas del modelo de sociedad que comenzó a imponerse a nivel mundial a partir del siglo XVII y que ahora está llegando a su etapa final. (pp. 19-21, p.64)

Acoger la diversidad pasa por una actitud de cuidado, más que un tema, relacionado a altruismo o benevolencia, cuidado entendido como la energía que posibilita prestar atención a las infinitas y muchas formas de vida, siempre entramadas. Grey (1993) afirma que "se trata del brote de una complicidad que está cuidando y prestando atención, apreciando, nutriendo los vínculos orgánicos de interconexión entre todos los seres vivos. Cuidado es entonces, el dinamismo básico de complicidad, en lugar del dinamismo de control, indiferencia o imparcialidad". (pp..87-88). El cuidado requiere de un mirar más detenido, una escucha paciente, dejarnos absorber por los gestos, modos y pensamientos, significa que cuanto más se atiende, más profundamente se cuida.

En la contemporaneidad cuando se piensa desde la complejidad de la vida o de forma planetaria, como ha sido explicado, característica de todos los tiempos y espacios, exige que como personas busquemos en nuestras prácticas cotidianas elementos que nos conduzcan a nuevas lecturas de las realidades vividas, para adecuarnos a las exigencias que emergen de las interacciones sociales. Por lo tanto, en este trabajo para profundizar sobre 
los significados de diversidad y cuidado, me situaré desde los ámbitos de la educación y de la religión, y a partir de una mirada feminista, como ámbitos y miradas a partir de las cuales construyo y resignifico de forma crítica las interacciones sociales, como parte de la experiencia que habito.

\section{Educación, diversidad y cuidado}

Una mirada crítica, tanto a la educación como a la religión nos permite entender la lógica occidental, dominante, dualista, cartesiana, desde donde ambos campos de acción sientan sus bases, se anclan y se reproducen. Pero, al mismo tiempo, a partir de los cuales se desintegran las percepciones, sentimientos, emociones, sensaciones, ideas e imágenes que dan fe de nuestro lugar y nuestro ser diverso en el mundo. De manera particular, los modelos positivistas de la educación, por ejemplo, crean un ser todopoderoso, el maestro, que tiene el conocimiento válido, designado como verdad eterna, opuesto a un saber no científico. Y que tiene el deber de transmitir ese conocimiento a los alumnos, quienes lo reciben sin poder transformarlo, ni digerirlo, ni cuestionarlo. Además, esa verdad única, depositada en los alumnos, quienes son considerados objetos, se piensa independiente del ambiente que la produce.

Es frente a ese sistema de pensamiento y acción educativa que un pensamiento complejo, por lo tanto, vincular, posibilita acciones y crea áreas de resistencia simbólica y espacios de reversión de imaginarios, a partir de las cuales se fundamentan propuestas educativas y propuestas de comprensiones de lo religioso que son xenófobas, sexistas, patriarcales, de negación a la diversidad y de exclusión, ambas acciones que trascienden fronteras y parecen resistir ante cualquier crisis. Hasta la Organización de las Naciones Unidas para la Educación (UNESCO), ha señalado sobre la magnitud de la exclusión en la educación, en América Latina y el Caribe. En los resultados de un informe "Inclusión y Educación: todos sin excepción” (2020) publicado, mientras escribimos este texto, señala que:

Alrededor de una cuarta parte de los países de América Latina y el Caribe cuentan con leyes de educación inclusiva que abarcan a todos los educandos. Chile y Paraguay se destacan por ser dos de los cinco países en el mundo que tienen leyes de educación inclusiva que abarcan a todos los estudiantes. (párr.1)

Se puede concluir que esta realidad no es fruto de la situación de crisis causada por el Coronavirus, sino que se trata de una situación que se acumula de años.

El mismo informe destaca que:

La diversidad no se refleja adecuadamente en los sistemas educativos. Solo siete países de la región reconocen el lenguaje de señas como idioma oficial. Los estudiantes con discapacidades suelen necesitar infraestructura y materiales adaptados, pero solo el 29\% de las escuelas de la región han hecho los cambios necesarios. En Costa Rica, alrededor del 55\% de los que respondieron a una encuesta nacional sobre discapacidad informaron que los centros educativos no eran accesibles y carecían de rampas, alertas visuales y sonoras, barras de agarre y otras adaptaciones". Y, además, "el género es otro de los temas que abordan muchos programas de formación docente antes de que los maestros empiecen a trabajar. El Programa de Educación en Sexualidad de Cuba tiene por objeto fortalecer la formación docente y prevenir las infecciones de transmisión sexual". (UNESCO, 2020, párr.10-11)

Reconozco la gran cantidad de acciones promotoras de formas diferentes de pensar y hacer educación, lejos de mera transmisión de conocimientos desvinculados de su ambiente, totalmente fragmentados, que establecen relaciones asimétricas. Sino que más bien, se ocupan en pensar educación en relación con los aprendizajes no como apropiación pasiva de verdades universales, sino como actividad productiva y creativa en la que estamos involucrados como sujetos sociales, que convivimos en instituciones que están en interacción con un medio ambiente en permanente transformación. 
La pandemia provocada por el Covid-19 ha hecho que, hoy más que nunca, las tecnologías de la comunicación, se vuelvan condición necesaria, aunque no son suficientes, para hacer lugar a la potencia divergente de la imaginación y la creatividad, provocando rupturas drásticas con las modalidades estandarizadas de enseñanzaaprendizaje (Najmanovich, 2009, p. 19).

Además, se debe reconocer que el modo educativo que hemos heredado y el que compartimos es un modo patriarcal, característica que se mantiene con el uso de tecnologías en la educación, manteniéndose la herencia de una pedagogía de crueldad, de la que nos advierte Segato (2015),

El paradigma de explotación supone una variedad enorme de formas de desprotección de la vida humana, y esta modalidad de explotación depende de la disminución de la empatía entre personas que es el principio de la crueldad. De ahí hay sólo un paso a decir que el capital hoy depende de una pedagogía de la crueldad, de acostumbrarnos al espectáculo de la crueldad. (p.1)

Por lo tanto, la crisis que hoy día se vive no invita a un mero cambio de modelos, teorías y paradigmas, sino a una profunda mutación de nuestras formas de conocer. La crueldad aprendida, visibilizada en la indolencia y la indiferencia, llama a que la educación se abra a nuevos saberes y al reconocimiento de actores que la misma sociedad produce en todos los ámbitos, pero que, al mismo tiempo los trata de ignorar. Ante esto, no estaría mal recordar a Freire (1979), citado por Dos Santos y Sirley (2003), cuando afirmaba:

La posibilidad de discernir, comparar, escoger, programar, evaluar, nos compromete a arriesgarnos, a hacernos seres de la decisión y por tanto seres éticos. Por eso es imperativo ético luchar contra la discriminación. Discriminados por deficientes, pobres, negros, mujeres, indios, homosexuales, trabajadores, árabes, africanos, etc. Tenemos que luchar contra la discriminación. La discriminación nos ofende porque hiere la substantividad de nuestro ser. (p.1)

La voz de este gran pensador de todos los tiempos, se une a la de otros tantos que proponen formas de reinventar la enseñanza y de aprender en el siglo XXI. Y, en estos momentos, en el que el Covid-19, ha revelado todavía más los niveles de exclusión e inequidad, se debería aprovechar para pasar a un mundo que no solo valore, sino que acoja la diversidad.

Adoptar el abordaje de la diversidad implica reconocer las diferencias y a partir de ellas, realizar la gestión del aprendizaje, teniendo presente el ideario político-pedagógico de una educación capaz de atender a todas las personas que participan de la experiencia de aprendizaje, considerando como principio de su propuesta las desigualdades sociales. Pero también, es de saber que cualquier impulso para conectarse tiene lugar en medio de las personas desoladas y la comunidad oprimida. Significa que tener una mirada compleja, una mirada que nos lleva a sabernos conectados con las otras personas y, por lo tanto, a tener en cuenta las diferencias, se trata de una acción ética. Y es así donde entendemos el peligro de la separabilidad que tanto insisten los sistemas dominantes.

Sabemos ahora que siempre hemos estado en peligro, en separación, pero hasta ahora no habíamos tocado nuestra fuerza. Si esto suena una afirmación exagerada, piense en la forma en que organizamos nuestro mundo, nuestras instituciones y nuestras relaciones, siguiendo la forma en que entendemos la persona humana. ¿En qué medida están todos estructurados por la noción de separación y en el nivel de subjetividad, por el individualismo y sus consecuencias de largo alcance? El individuo merece lo que obtiene y obtiene lo que merece, sigue siendo un refrán muy popular en muchas de nuestras culturas. Y, muy común escucharlo en los ambientes escolares: "aprobó porque se dedicó". De ahí que la transformación política y social debe ser el primer nivel de nuestra conciencia filosófica y orden simbólico.

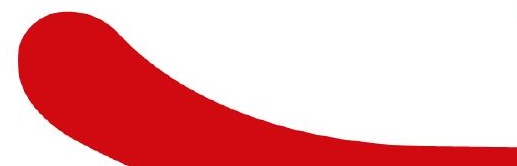


Por eso la aceptación de la diversidad debe ser entendida como la aceptación de realidades plurales y, por lo tanto, tiene muchas y complejas implicaciones. Al respecto, Dos Santos (2003, p.5) señala:

- Facilitar la flexibilidad curricular;

- Cambiar la cultura de la institución y de las estructuras educativas;

- Superar la cultura del individualismo;

- Crear espacios adecuados de convivencia, favoreciendo relaciones personales entre profesores, comunidad y alumnos;

- Considerar la educación como posibilidad de que todas las personas trabajen según sus potencialidades, desarrollando actividades abiertas que generen la autoestima;

- Considerar la diversidad, no como una técnica pedagógica o una cuestión meramente metodológica, sino como una opción social, cultural, ética y política.

Por lo tanto, una educación para y desde la diversidad y el cuidado no sólo busca cambios de contenidos curriculares, sino que al alejarse de una pedagogía de la crueldad se interesa porque quien participa viva su experiencia a través de prácticas políticas, teóricas y de autoanálisis, que les permitan entrar en relación con las experiencias históricas de los grupos vulnerables de la sociedad y así generar transformaciones, superando el individualismo y elevando una dinámica vincular que abra a espacios de convivencia. Espacios en los cuales se pueda pensar, crear, producir y compartir nuevos modos de enseñar y sobre todo nuevas formas de aprender juntos, para poder crear otros modos de vivir. En palabras de Najmanovich (2020):

Hay que construir otra estética, otra ética como personas conviviendo en la naturaleza. Hay que salir de la concepción individualista, de la concepción atomista, en la que hemos sido creados. Hay que dejar de pensarnos como individuos y pasar a pensarnos como singularidades entramadas. (p.5)

Pensarnos singularidades entramadas nos permite, sabernos conectados como agentes pensantes y, por lo tanto, tener presente el cuidado que es necesario para mantener esa conexión. Un cuidado que como fue dicho en párrafos anteriores, tiene que ver con la atención de conectar con el otro y también con habitar la experiencia que estoy viviendo y el vínculo que estoy viviendo. Además, vale señalar que la palabra cuidado viene del latín cogitatus, la cual tiene la misma raíz que cogito, llevar adelante, hacer avanzar, conocer. Esto me dice que no puede haber conexión sin cuidado, pero tampoco puede haber cuidado sin conocer o, lo que es lo mismo, sin hacer avanzar. Esto nos lleva a pensar en la educación y la forma en que se lleva a cabo, la cual no debería ser pensada ni practicada como algo fijo, estancado, sino algo en movimiento, por medio de la cual se avanza hacia el reconocimiento de las conexiones o vínculos.

\section{Religión, diversidad y cuidado}

La misma lógica que construye una visión de educación, de verdades eternas, de conocimientos fijos y sostenedora de una pedagogía de la crueldad, es la misma lógica que sostiene una visión de religión mágica, y una imagen de un dios trascendente, súper poderoso, masculino, castigador, y, a la vez, sostenido por una espiritualidad dominante que genera esperanza pasiva y creación fragmentada, que permite se demonice la diferencia y la diversidad.

Es ahí, la urgente necesidad de abordar el tema de la religión en clave de diversidad y cuidado, reconociendo que en la actualidad las fronteras disciplinarias y sectoriales se están disolviendo y se están expandiendo los abordajes complejos en red, que nos permiten encontrar un mundo integrado y, al mismo tiempo, cambiante y diverso. Y que hace emerger una relación con lo sagrado fundamentada en el amor (el logos encarnado), la realidad incondicional que actúa incondicionalmente, que actúa en la historia, dándole la real posibilidad de la vida en paz, en la comunicación transparente, y en la comunión. 
Sin embargo, hay que reconocer que, desde un pensamiento teológico tradicional, este mundo naturalmente tan cambiante, se continúe mirando desde las anteojeras mecanicistas de determinismos raciales, sexuales o de posición social y, por lo tanto, a lo sagrado como espacio simbólico colonial y entonces, negatorio de la diversidad y el cuidado en igualdad de condiciones, rompiendo de esta manera, la socialización que provoca el amor.

En este sentido, al pensar en religión desde una lógica dominante y mecanicista, no se puede dejar de lado que, ha sido uno de los campos sociales centrado en la norma y constructor de normatividades, lo que, explicado desde la comprensión de la sociedad disciplinaria, que es también una sociedad normalizante, es así descrito por Foucault (1976):

De una manera aún más general, puede decirse que el elemento que va a circular de lo disciplinario a lo regularizador, que va a aplicarse del mismo modo al cuerpo y a la población, que permite controlar el orden disciplinario del cuerpo y los acontecimientos aleatorios de una multiplicidad biológica, el elemento que circula de una a la otra, es la norma. La norma es lo que puede aplicarse tanto a un cuerpo al que se quiere disciplinar, como a una población a que se pretende regularizar. (pp.228-229)

Desde la experiencia de muchas mujeres y hombres, en su papel normalizador la religión se destaca como lugar privilegiado de poder fragmentador del cuerpo y de las relaciones. Por esta razón, dentro de una propuesta de cambio de mirada y de pensamiento invita, por un lado, a integrar cuerpo/mente/corazón/ alma/sentimiento sexual dentro de una totalidad de autocomprensión relacional. Y, por otro lado, a tener presente un grupo comunitario/nación/grupo cultural/tradición religiosa, de manera que ambas acciones contribuyan con el fortalecimiento de una memoria comunitaria, que permita dejarnos afectar de otras experiencias. Al reconocer la conectividad entre las personas, lejos de suprimir la diferencia, nos potenciamos y así damos la bienvenida a la diversidad y para interactuar de forma creativa con las consecuencias políticas y sociales (Grey, 1993). Esto sólo es posible en una dinámica de aceptación y, por lo tanto, de reconocimiento del otro, así el otro no se queda en lo invisible.

Hay quienes afirman que las mediaciones entre lo humano y lo no humano es donde la invisibilidad es menos rara (de Sousa 2020, p.34), y aseguro que esta afirmación cabe muy bien, en la imagen que sobre lo sagrado se ha construido, desde un pensamiento dominante y exclusivista. Dicho de otra manera, cuando se piensa la relación con lo sagrado alejado de la historia, o su intervención sólo en los casos en que pueda interesar a los grupos dominantes. Ante esto, como estudiosa de los textos bíblicos, puedo sugerir que hay diversas maneras de pensar la divinidad y de enunciar la relación entre lo humano y lo no humano, de manera que la invisibilidad no sea la característica.

Con frecuencia nuestras lecturas de los textos bíblicos están enfocadas en los grandes acontecimientos, conocidos algunos, en América Latina como los acontecimientos fundantes del pueblo de Dios que está en la Biblia. Desde estas lecturas, las preocupaciones andan por el Dios todopoderoso, fuerte, que escucha el grito de quienes claman por justicia, esclavitud y plagas. Se destacan grandes figuras masculinas que denuncian y anuncian, fieles, al proyecto de ese dios que también se vuelve implacable contra quienes lo desobedecen, que son distintos. Se reconocen también historias en las que las mujeres, madres, esposas, hermanas, tienen un rol importante en los textos. En la propuesta de lectura que hago, preocupada por las injusticias y las acciones de liberación que acontecen en forma general, me ocupo de cuestiones concretas que apuntan a las relaciones entre las mujeres y los hombres y de estos con el entorno. Además, se suma una gran inquietud por traer a la discusión "conocimientos otros" provocados no sólo por los textos bíblicos, sino también por las interconexiones con los contextos desde donde se hace la lectura.

Reconozco que hoy día sobresale la dificultad de imaginar el futuro en un presente cada vez más violento, más discriminador, más desigual e inequitativo. Desde ese panorama me atrevo a proponer mirar a las mujeres en el Antiguo Testamento, a partir de un fuera del texto que cada vez más nos invita a tener la diversidad y el cuidado como claves. Desde el punto de vista epistémico, significa reflexionar creativamente sobre la realidad y el texto, para, con palabras de Boaventura de Sousa Santos (2011) ofrecer un diagnóstico crítico del 
presente que, obviamente, tiene como su elemento constitutivo la posibilidad de reconstruir, formular y legitimar alternativas para una sociedad más justa y libre, y de manera urgente para una vida de equidad para las mujeres. Y esto es, lo que en sentido general considero como el fin último de toda lectura de la Biblia. De tal forma, que me acerco al tema propuesto no simplemente en términos de los estudios académicos de la diversidad y el cuidado, sino en términos de una teoría política feminista y una lectura bíblica crítica de la liberación. Para esto, es importante una aproximación cuidadosa que me permita conocer el tipo de lectura al cual me refiero, así como también ver cómo aplicarla:

\section{a. Caracterizando la lectura}

Vale señalar que la base teológica de mi lectura es feminista, crítica y de la liberación. Esta se fundamenta en afirmar la teología como: • lugar de la palabra de las mujeres sobre Dios, • lugar de construcción de la ekklesia de las mujeres. Y, por lo tanto, $\bullet$ lugar desde el cual pueden ser articuladas transformaciones políticas-culturales, religiosas y pueden ser hechas acciones en nombre de un pluralismo democrático (Schüssler, 2009). Esta comprensión teológica, me sugiere una manera distinta de leer y entender la biblia:

En un primer lugar, Schüssler (2009), señala que se trata de

Un libro en el que una rica pluralidad de voces ciudadanas discute entre ellas, se complementan y mantienen viva la visión de la justicia divina, el cuidado y el bienestar. Estas voces se enriquecen democráticamente por los contextos en los que se escuchan e interpretan. (p.3)

En segundo lugar, los denominados estudios bíblicos, al igual que otras formas de conocer, son una construcción social y dependen tanto de las creencias y valores de quienes leen como de su apego a métodos e interpretaciones. La propuesta epistemológica y la perspectiva pedagógica constituyen dos elementos clave para reflexionar sobre una mirada crítica de la biblia y el aprendizaje que resulta de esta manera de trascender las aproximaciones tradicionales, pero cuestionar también aquellas lecturas bíblicas que, sin alejarse de un paradigma estandarizador, normatizador, donde todo está predeterminado, se llaman liberadoras. En este sentido, la biblia tiene un papel determinante en la vida de muchas mujeres. Así como su lectura puede ser limitante para sus anhelos, también puede servir de luz para la potenciación de su identidad en cuanto sujeto de pleno derecho.

De ahí, que la lectura de la biblia se vuelve una tarea desafiante ante las experiencias vitales, marcadas por pobreza y violencia de mujeres, niñas y niños, también de hombres en América Latina y Caribe. Considero, entonces, que la lectura de la biblia, como productora de conocimiento, como señalé en párrafos anteriores, debe ser estudiada y reflexionada desde la perspectiva de lo vincular ${ }^{2}$, es decir, desde distintos modos de interacción. Estas formas no sólo me permiten ver los textos de manera más amplia, con lo cual consiga prestar atención a otros rostros, a otras situaciones; sino que implica cambiar la propia mirada en las formas de abordar el texto para una mirada compleja.

Esto me permite, primero, entender el texto como un tejido de componentes heterogéneos inseparablemente asociados, y segundo, puedo constatar las acciones, interacciones, retroacciones, determinaciones, que constituyen tanto el texto bíblico como un todo, así como quien lee desde su propio entorno también complejo. Todo esto, permite que transitemos por los ámbitos de lo complejo, pero también invita a prestar atención a la diversidad como elemento generador de cambio de miradas. $\mathrm{Y}$ con esto promover la emergencia de un saber vital en el que se entrame lo afectivo, lo sensible y lo cognitivo.

2. Najmanovich (2008, p. 87) afirma que "pensar desde lo vincular es un modo de interacción, una actividad poiética (productiva [generativa]) que deja una estela en su navegar: el conocimiento". 
Esa propuesta, de cambio de mirada no deja de lado y, más bien promueve, las miradas críticas y complejas sobre los estudios bíblicos tradicionales, pero también sobre las enseñanzas y aprendizajes sobre Dios o, más bien, sobre las experiencias de Dios en la vida de las personas, que están en los textos y fuera de ellos. Es de esta manera, que vengo insistiendo desde trabajos anteriores, que nuevas maneras de abordar los textos bíblicos tienen que ver con no perder de vista la realidad del tejido fenoménico en el cual estamos y que constituye nuestro mundo. Es desde ahí que podemos hablar, percibir la diversidad, pero también el cuidado que sólo podemos conocer por medio de ella. Desde estas afirmaciones invito a que entremos en los textos, sabiendo que no es el texto en sí, sino el modo en que nos aproximamos a este, de aprehender y hacerlo trabajar. Hacer lugar a la diversidad supone aceptar la radical singularidad de toda existencia. Por esta razón, como una puesta en práctica de la hermenéutica de la sospecha, será necesario desenmascarar los textos patriarcales, racistas, clasistas y sus interpretaciones.

\section{b. Un ejemplo de lectura: de diversidad y cuidado en 1 Reyes 3,16-28}

16. Vinieron por entonces al rey dos prostitutas y se presentaron ante él.

17. Una de las mujeres dijo: «Óyeme, mi señor. Yo y esta mujer vivíamos en una misma casa, y yo he dado a luz, estando ella conmigo en la casa.

18. A los tres días de mi alumbramiento, también dio a luz esta mujer; estábamos juntas, no había ningún extraño con nosotras en la casa, fuera de nosotras dos.

19. El hijo de esa mujer murió una noche, porque ella se había acostado sobre él.

20. Se levantó ella durante la noche y tomó a mi hijo de mi lado, mientras tu sierva dormía, y lo acostó en su regazo, y a su hijo muerto lo acostó en mi regazo.

21. Cuando me levanté por la mañana para dar de mamar a mi hijo, lo hallé muerto; pero fijándome en él por la mañana vi que no era mi hijo, el que yo había dado a luz.»

22. La otra mujer dijo: «No, todo lo contrario, mi hijo es el vivo y tu hijo es el muerto.» Pero la otra replicó: «No; tu hijo es el muerto y mi hijo es el vivo.» Y discutían delante del rey.

23. Dijo el rey: «Esta dice: "Mi hijo es éste, el vivo, y tu hijo es el muerto." Pero la otra dice: "No, tu hijo es el muerto, y mi hijo es el vivo."

24. Dijo el rey: «Traedme una espada.» Llevaron una espada ante el rey.

25. Dijo el rey: «Partid en dos al niño vivo y dad una mitad a una y otra a la otra».

26. La mujer de quien era el niño vivo habló al rey, porque sus entrañas se conmovieron por su hijo, y dijo: «Por favor, mi señor, que le den el niño vivo y que no le maten.» Pero la otra dijo: «No será ni para mí ni para ti: que lo partan.»

27. Respondió el rey: «Entregad a aquélla el niño vivo y no le matéis; ella es la madre.»

28. Todo Israel oyó el juicio que hizo el rey y reverenciaron al rey, pues vieron que había en él una sabiduría divina para hacer justicia."

Antes de detenerme en el texto, sobre el cual no pretendo realizar ningún estudio exhaustivo ${ }^{3}$, vale señalar que autores bíblicos no tienen problemas en afirmar que la antigua sabiduría, en su fase oral y preliteraria, se enraíza en el suelo del pueblo, entendido éste como la base sociológica más extensa de una población en una época determinada. En la convivencia diaria de unos con otros se aprende de hecho a sortear los peligros que nos acechan, a aprovechar toda ocasión oportuna, a utilizar debidamente el tiempo y nuestras cualidades, a descubrir el valor de las cosas, el sentido de los acontecimientos y de la vida misma (Vílchez, 1995)4. En tanto que Pérez (1971) explica que

\footnotetext{
3. Para profundizar sugiero: Nancy Cardoso Pereira (1997). "Prostitutas-madres-mujeres-obsesiones y profecías en 1Reyes 3,16-28” en Ribla 25. Quito (Ecuador): RECUE.

4. Este mismo autor afirma, además, que "la sabiduría está relacionada con habilidad y pericia. Una de las primeras cosas que llaman la atención del que observa el comportamiento normal de los hombres es la habilidad que algunos poseen para ciertas actividades. Es admirable la pericia y destreza que manifiestan los que por su profesión manipulan materiales útiles para la vida normal, como son los objetos de uso doméstico, el vestido, la vivienda, o los metales y materiales nobles para la ejecución de obras de arte profano o religioso”. (Vilchez, 1995, p.17)
} 
Israel, como todos los pueblos, observó e intentó penetrar la naturaleza de las cosas con el fin de ordenarlas a su provecho. Eso fue en un principio la sabiduría: la facultad de distinguir lo útil de lo nocivo, lo bueno de lo malo. (pp.15-16)

Tanto Vilchez como Rodríguez, destacan a Salomón como el mayor acervo de sabiduría en Israel (1Reyes 5, 10). Sin embargo, no son pocos los autores que entienden que Israel reconoció desde un principio la sabiduría divina (cfr. Génesis 2, 17; 3, 5. 22) caminos que solamente Dios conoce (cfr en Job 28 el precioso elogio de la Sabiduría cuya inaccesibilidad al hombre pone de relieve) y comunica a determinadas personas: a José, que interpreta los sueños del faraón (Génesis 41, 39), a Moisés y los ancianos con el fin de que puedan gobernar el pueblo de Dios (Números 11, 17 ss.), a los constructores del Tabernáculo (Éxodo 35, 31 ss.)" (p.16). Pero, también a "todas las mujeres hábiles [con habilidad] en hilar, hilaron pelo de cabra..." (Éxodo 35, 25s).

Al texto 1 Reyes 3,16-28, le antecede la limitación que tiene Salomón de no saber gobernar "yo soy joven y no sé cómo gobernar". Con esto, se muestra carente de sabiduría o "la argumentación es que la tarea es mucha y requiere de una sabiduría dada por Dios" (Pablo Andiñach,1996, p.24). Lo que significa que Salomón no parece tener la capacidad de, $\mathbf{L} \mathbf{I}_{\mathbf{\tau}}^{\mathbf{I}}$ yadá “conocer", término que puede tener el sentido de "cuidado", "saber", y lo justifica por ser joven (1Reyes 3,7s). Esto puede estar indicando que no está siendo aceptado en sus funciones. ¿Por joven o por no tener la capacidad?

Se destaca, en la segunda parte del texto, 1 Reyes 3,16, dos mujeres madres y, además calificadas como prostitutas, vienen a presentarle un caso sobre sus hijos. Mi sospecha es que este es el caso que lo consagra como rey sabio. Con este acontecimiento y desde quienes los apoyan, aprovecha para legitimarse como sabio ante todos los demás "de todas las naciones venían a escuchar la sabiduría de Salomón, de todos los reinos del mundo que oían hablar de su sabiduría” (1 Reyes 5,14; cf. 10,24; 2 Crónicas 9,23). ${ }^{5}$ Ciertamente, lo hace con una historia que tiene unas características muy especiales: historia de mujeres, entre mujeres y relacionadas con sus hijos. Una historia que arrastra lo cotidiano y, por lo tanto, la tradición más antigua del ejercicio del sabio.

El texto inicia con una información que nos sorprende: "vinieron al rey dos nł̧ Zanáh, raíz cuyo primer significado (refiere a alguien muy bien alimentado y por lo tanto desenfrenado); cometer adulterio (por lo general de la mujer y menos frecuente se destaca el significado de simple fornicación, rara vez de acto involuntario); una figura frecuente es la de cometer idolatría (siendo que al pueblo judío se le consideraba esposa de Jehová):- adulterar, apartar, cesar, cometer fornicación, dejar, infiel, ir, prostituir y ramera. ${ }^{6}$

Esta información nos obliga a volver a preguntar ¿por qué tienen que venir dos mujeres "infieles" donde el rey, son infieles a quién? Se trata de un tema de la vida cotidiana, lo que nos invita a preguntar, ¿que tiene el rey que ver con ese tema? Sabemos que Salomón ha ido a pedir sabiduría ante Yabveh, le pidió que lo haga sabio, “...para discernir entre el bien y el mal” (1Reyes 3,9). La otra cuestión que llama nuestra atención es ¿por qué en el texto no hay preocupación por preguntar por el padre o los padres de las criaturas? Además, ¿por qué quiere determinar entre lo bueno o lo malo?’. Se puede observar, que el texto se envuelve en confusiones, en relación a las mujeres, pues el mismo término con que son identificadas no hay un acuerdo en cómo entenderlo: mujeres “infieles", "que van", "que dejan”.

\footnotetext{
5. La fama del buen gobierno de Salomón traspasó las fronteras de Israel, como se encargan de proclamar un tanto exageradamente los historiadores cortesanos: Como caso emblemático se recuerda el de la reina de Sabá (cf. 1 Reyes 10, 4.6-8; 2 Crónicas 9,3.5-7). (Vilchez, 1995, p.23)

6. Tִ Zaná. Consultar bttps://mmm.palimpalem.com/5/SETI/index.btml?body16.btml

7. Aunque es una característica de la sabiduría antigua, el distinguir "lo bueno y lo malo". En el contexto del texto vale recordar, la conexión que tiene la Sabiduría de Salomón con el Pentateuco, específicamente, con Gn 3,5, donde la serpiente señala que el conocimiento "del bien y del mal" hará como dioses a la pareja humana. (Andiñach, 1996, p.24).
} 
Frente a lo anterior, lo que sí me queda claro es que el rey parece tener no sólo la sabiduría, sino que aparece justificada su actuación. Sin embargo, se queda solapada la intención de un personaje que está ávido de poder y, peor, que captura el saber de otros y se lo apropia. Con la mente puesta en esto que me llama a la atención, vuelvo al texto, pero me niego a quedar atrapada en las vías de interpretación con las que suele explicarse este texto. Prefiero buscar otras entradas y preguntar ¿quién tiene una actuación diversa a lo esperado? y, por lo tanto, una actuación que retoma lo tradicional de la sabiduría, la capacidad para discernir más allá de lo común, o mejor, más allá de lo "normal".

Como ha sido dicho, en partes anteriores de este trabajo, nuestra cultura se ha organizado desde una perspectiva normalizadora, que nos lleva a deshabitar la experiencia del encuentro. De ese modo la diversidad se licúa y queda subsumida en la diferencia, capturada por lo normal como patrón de comparación. Sin embargo, la singularidad de la existencia es algo que sabemos en tanto seres vivos, pero olvidamos, desvalorizamos o negamos porque hemos sido formados en una cultura de estándares, normalizadora. Lo "normal", la modernidad lo ha elevado a un lugar privilegiado del imaginario social. Lo convierte en un arquetipo omnipresente para medirnos y modelarnos, pretende fijar los límites de nuestros movimientos, de nuestros deseos, de nuestro comportamiento visceral, de nuestro lenguaje, inclusive de nuestra sexualidad. $\mathrm{Y}$, principalmente, de nuestra manera de ver e interpretar el mundo y los acontecimientos. Se usa la palabra normal para decir lo más común -estadísticamente- pero también la cultura nos susurra al oído que el normal es excelente, es lo que todos deberíamos ser. En este sentido, autores como Orozco (2014) afirman que

Lo normal es aquello que se considera natural, que fluye y ocurre espontáneamente y por esta razón simplemente es aceptado, es lo común, lo que no afecta ni molesta a la propia persona ni a los demás, por esta razón nadie parece preocuparse ni inquietarse por eso llamado normalidad. (p.2)

Entonces, lo normal es que el rey haya actuado como actuó. ¡Y nadie dice más nada! Con esto se puede confundir la mirada atenta que sobre eso deben tener los más ancianos y las mujeres sabias, que optan por la vida. Que son las personas consideradas sabias tanto en la cultura antigua que está en la Biblia (como las mujeres parteras en Exodo 1,8), así como también en nuestras culturas. En el texto la voz de los ancianos se silencia frente al rey, y lo presentan como el que pone las reglas, dejando atrás la sabiduría que está enraizada en el suelo del pueblo.

Sospecho que en este texto debemos ir más allá de lo que se quiere presentar como "normal" y desencubrir la actuación que irrumpe con una propuesta diferente, fuera del patrón. Centro mi atención en la madre, quien desde sus afectos detiene la máquina de muerte. Esa a la que el rey acostumbra a maniobrar. Él no tiene otra solución que la muerte. Ella, la madre, manda a parar y hace una opción por la vida, afirmando entonces, la sabiduría que reclama la solución de los problemas cotidianos optando por la vida. De esta manera, sale a la luz la sabiduría que viene de Dios, la cual es capacidad de discernimiento. Para que la diversidad emerja a la superficie y no se quede atrapada en la diferencia (pues esto no se puede negar, el rey y las mujeres son diferentes, las dos mujeres también lo son, pero no basta con saber esto).

El error sería pensar que el rey es sabio, cuando, simplemente intenta subsumir la diversidad, para actuar bajo el patrón de lo normal. Con el texto se pretende hacer que todos piensen igual que el rey, que se muevan por la muerte. Es así como aparece también el tema del cuidado. La madre se revela por medio de la dinámica vincular que la conecta con el hijo, dejando con esto trasparecer la práctica del cuidado esencial: "el cuidado como principio que acompaña al ser humano a cada paso, en cada momento, en cualquier circunstancia, en el tiempo y en los contra-tiempos" (Boff, 2002, p.130). 
Pero más todavía, con la actuación de la madre nos encontramos con el cuidado como propuesta que acompaña la diversidad. Una mirada distinta no complaciente, un pensar y actuar, pero desde otra lógica, es una acción cuidadosa. El cuidado en la constitución de los modos sociales de organización en una ecología, nos recuerda que los compromisos contemporáneos con el cuidado son múltiples y, a veces, contradictorios: el cuidado es una categoría disputada en el análisis crítico de la reproducción social, pero también recientemente se ha vuelto omnipresente en el marketing moral y la gobernanza neoliberal, marcando, un orden generalizado de la moral biopolítica individualizada, a pesar de esto, el cuidado es un espacio de autonomía y organización que es capaz de establecer nuevos motivos de posibilidad en y contra los procesos de aniquilación que desencadena el capitalismo (Najmanovich, 2019).

Retomando el actuar de las mujeres en el texto bíblico, nos damos cuenta que a pesar que se quiere mantener fija el binario común madre/prostituta, se escapa para dejar ver que ser madre no es la misma cosa, revelando que "una puede expresar sus instintos naturales en la forma sacrificial y amorosa, mientras que la otra que no cumple con este patrón se deja solo como prostituta y, por lo tanto, carente de un discernimiento ético" (Cardoso, 1997, p.34). De esta manera, el tema del cuidado puede correr el riesgo de quedarse atrapado en los moldes que funcionan para los sistemas dominantes. Es por esto que, Leonardo Boff (2002) nos recuerda que "el cuidado se encuentra en la raíz primera del ser humano, antes de que haga nada...es un modo de ser esencial, siempre presente e irreductible a otra realidad anterior" (p.30). De cualquier manera, el cuidado como un todo entramado, puede encontrar los sitios más fértiles en los bordes donde se intersectan diferentes mundos, no sólo rompiendo la separación entre las diferentes partes del conjunto institucional y entre el estado y la sociedad, sino también manteniendo el empoderamiento de la vida social en la gestión de la empresa de cuidado.

Las realidades actuales, que exigen pensar en desigualdades, violencias, exclusiones, pero también en los movimientos de resistencia, en las preguntas hechas por las mujeres, que cuestionan el pensamiento y las formas patriarcales y dualistas de organizar la sociedad y la iglesia, todos estos elementos tienen que estar a la mano para los nuevos abordajes bíblicos. Los estudios de la Biblia deben ser hechos fuera de normas, lejos de los conceptos reguladores impuestos no sólo por métodos rígidos vaciados de criticidad, sino también de una visión de la religión como fenómeno alienante. De tal manera, que la propia experiencia religiosa se convierte en una intención propositiva que va de lo propiamente epistemológico a lo social, político y cultural.

Por eso, no me canso de proponer la vincularidad o conexiones como clave de lectura con la cual puede relativizar la simplicidad y descubrir la reconfiguración global de las formas de producir, validar y compartir el conocimiento. Y más todavía, poder proponer modos de convivir, centradas en la diversidad y el cuidado que nos abran a experiencias más liberadoras de lo sagrado.

\section{A modo de conclusión}

El trayecto de la reflexión planteada en este ensayo me llevó por varios momentos, que, aunque al final puedo presentarlos con un aparente orden, no son más que reflejo de la dinámica que me movía desde mi singularidad y con los vínculos que hacen parte de mi existir.

Primero, ese movimiento de mi propia singularidad es posible desde un pensamiento planetario que abre hacia el reconocimiento de la diversidad como categoría que pone en cuestión los estándares morfológicos de diferentes índoles y que al sacarnos de nuestro propio horizonte posibilita el encuentro con los otros. Significa que al salir de nosotras mismas y encontrarnos con el otro, negarnos las prácticas invisibilizadoras y, por lo tanto, se potencian las dinámicas vinculares, generadoras de afectos que traen consigo el cuidado mutuo. 
El reconocimiento y aceptación de la diversidad posibilita la emergencia del cuidado como categoría que brota de la atención que hacemos para mantener, continuar y reparar nuestro mundo, de manera que podamos vivir en él tan bien como sea posible. Ese mundo incluye nuestros cuerpos, nuestro ser y nuestro ambiente, todo lo cual buscamos para entretejer una compleja red de sostenimiento de la vida (Fisher y Tronto, 1990 citado en Tronto, 2006, p.5). De esta manera, el cuidado hace que se salga de lo individual para ir a lo social, procurando un existir en relación entre los seres humanos y los demás seres vivos. No existe sino en la misma trama de la vida. Por eso, sólo puede darse en el entramado con la diversidad.

Segundo, al dejarnos guiar por una mirada compleja, en coherencia con pensamiento planetario, tanto la diversidad como el cuidado sólo son posibles en la dinámica vincular de la propia vida. Por lo tanto, esto exige no sólo prestar atención al ser humano en su propio ser, en su manera de conectarse o no con los otros, sino también prestar atención al ambiente, al contexto sociopolítico, religioso y cultural donde se produce o se impide la emergencia vincular que posibilita el existir y, en consecuencia, que permite la manifestación de la diversidad y el cuidado.

Es necesario, entonces, estar atentas al contexto desde las crisis antiguas y nuevas que lo caracterizan, pero sin permitir que sean la última palabra. Por eso, al mirar de forma compleja las prácticas cotidianas nos permitimos transitar por ámbitos como la educación y la religión, y poder ver cómo esas crisis se pueden leer a través de ellas, pero, sobre todo, como dos ámbitos de generación de conocimientos y comportamientos, a partir del paradigma desde donde actúan, impactan cotidianamente en la comprensión de la diversidad y el cuidado, ya sea para negarlos o para hacerlos posible.

Tercero, en este trabajo, después de una mirada crítica a la educación centrada en un paradigma normalizador y una pedagogía de la crueldad, con la que se promueve las verdades únicas, se opta por una educación que se hace desde el abordaje de la diversidad, centrada en la generación de conocimientos vinculados al cuidado vital. Una educación que reconoce las diferencias en la gestión de los aprendizajes. Pero, además, se interesa por generar prácticas políticas, teóricas y de autoanálisis entre los sujetos participantes, que les permiten entrar en relación con las experiencias históricas de los grupos vulnerables de la sociedad para generar transformaciones.

Por último, se propone una mirada crítica a la religión que promueve la muerte, por medio de la fragmentación y las verdades únicas y eternas. $\mathrm{Y}$ esto se hace por medio de un abordaje vincular y feminista de un texto bíblico. Con esto, nos permitimos elevar una nueva comprensión, más allá de estándares normalizadores de cuadriculas morfológicas (como plantea Judith Butler). Y ver la diversidad también en la actuación de la madre que invierte el patrón de lo normal, representado en la orden de muerte a los inocentes, dada por el rey. Dejando entonces, trasparecer el cuidado como esencia de la vida humana.

Finalmente, es importante destacar que abordar el tema de la diversidad y el cuidado, exige adentrarnos en la propia experiencia humana, pero, sobre todo, tiene que ver con los modos de pensar el mundo, las relaciones, los vínculos. Por esta razón, me queda claro que debe ser trabajado desde contextos concretos de nuestras vidas, para que no se queden en teorías, pues tienen que ver con acciones concretas. Esto nos permite evocar, aunque no sea el momento de abordarlo, que se trata de un tema ético.

\section{Referencias Bibliográficas}

Andiñach, P. (1996). El Pentateuco y sus proyecciones teológicas. RIBLA, (23), 23-26. Recuperado de bttps://bit.ly/2BW7roj

Boff, L. (2002). El cuidado esencial-Ética de lo bumano, compasión por la Tierra. Madrid, España: Editorial Trotta.

Cardoso, N. (1997). Prostitutas-madres-mujeres-Obsesiones y profecías en 1Reyes 3,16-28. RIBLA, (25), $8-40$.

de Sousa, B. (2005). El milenio buérfano. Ensayos para una nueva cultura politica. Madrid, España: Trotta.

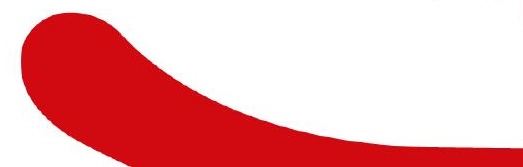


de Sousa, B. (2011). Introducción: las epistemologías del Sur. Barcelona, España. Recuperado de bttps:// bit. W/ 3 iNdSLB

de Sousa, B. (2020). La cruel pedagogía del virus. Buenos Aires, Argentina: CLACSO.

Dos Santos, M. (2003). Pedagogía de la diversidad. Desafio del Mundo Contemporáneo. Los profesores como intelectuales. Santiago de Chile, Chile: LOM.

Foucault, M. (1976). Defender la sociedad. Buenos Aires, Argentina: Fondo de Cultura Económica.

Kristeva, J. (1982). Women's Time. En N. Keohane, M. Rosaldo y B. Gelpi (comps.), Feminist Theory. A Critique of Ideology, Chicago, Estados Unidos de América: University of Chicago Press.

Najmanovich, D. (2009). Educar y aprender: escenarios y paradigmas. Propuesta Educativa, (32), 11-22.

Najmanovich, D. (2019). Banalidad del mal. Recuperado de https://bit.ly/2ZcD4TW

Organización de las Naciones Unidad para la Educación [UNESCO]. (23 de junio, 2020). Inclusión y Educación: todos sin excepción. Paris, France. Recuperado de bttps://bit.h//3gJPXeo

Orozco, S. (2014). Normalidad y anormalidad psicológica y niveles de prevención. Revista electrónica Psiconex, 6(9), 1-9. Recuperado de https://bit.ly/2ZUMNxp

Pérez, G. (1971). La literatura sapiencial. Madrid, España: Editorial PPC.

Schüssler, F. (2009). Democratizing Biblical Studies. Kentucky, Estados Unidos de América: Westminster John Knox Press.

Segato, R. (29 de mayo de 2015). La pedagogía de la crueldad [Audio de entrevista]. Recuperado de bttps://bit.ly/2W4miV5

Tronto, J. (2006). Vicious circles of privatized caring. En M. Hamington y D. Miller (Eds.), Feminist ethics and Public issues (pp.1-25). Maryland, Estados Unidos de América: Rowman and Littlefield Publishers. 